\title{
РЕЦЕНЗИИ
}

DOI: $\underline{10.17805 / g g z .2019 .5 .8}$

\section{ИФПИ как источник новых концепций в сфере гуманитарного знания}

М. В. Лихачев

Независимый исследователь, г. Рязань

Рецензия на электронную книгу: Луков В. А. ИФПИ: люди, идеи, проекmы, публикации: История, современное состояние, перспективы Института фундаментальных и прикладных исследований, его иентров и отделов. Публикации ИФПИ и его сотрудников в 2004-2018 годах. - М. : Изд-во Моск. гуманит. ун-та, 2019. - 524 c.

Ключевые слова: Институт фундаментальных и прикладных исследований; МосГУ; гуманитарные науки; тезаурусныий подход

\section{IFAS as a Source of New Conceptions in the Field of Humanities Knowledge \\ M. V. Likhachev Independent researcher, Ryazan}

This is a review of the e-book: Lukov V. A. IFPI: liudi, idei, proekty, publikatsii: Istoriia, sovremennoe sostoianie, perspektivy Instituta fundamental'nykh $i$ prikladnykh issledovanii, ego tsentrov i otdelov. Publikatsii IFPI i ego sotrudnikov v 2004-2018 godakh [IFAS: People, ideas, projects, publications: History, current state, prospects of the Institute of Fundamental and Applied Studies, its centers and departments. Publications of the IFAS and its employees in 2004-2018]. Moscow : Moscow University for the Humanities Publ., 2019. 524 p. (In Russ.).

Keywords: Institute of Fundamental and Applied Studies; Moscow University for the Humanities; humanities; thesaurus approach

В репозитарии научных публикаций Московского гуманитарного университета (МосГУ) размещена электронная книга ${ }^{1}$, посвященная истории, современному состоянию и перспективам Института фундаментальных и прикладных исследований - структурному подразделению университета, отме-

\footnotetext{
${ }^{1}$ Доступна по адресу: http://publications.mosgu.ru/index.php/main/catalog/book/15
} 
тившему в 2019 г. 15 лет со дня своего создания и все эти годы выступающему как источник новых концепций в сфере гуманитарного знания (Луков, 2019а). Автор этой книги проф. В. А. Луков, возглавлявший ИФПИ в 20042017 гг,, а в МосГУ пришедший еще в 1970 г., поэтому научная жизнь этого учреждения ему хорошо известна изнутри. К тому же, как руководитель научного блока университета в 2002-2015 гг. он на разных этапах развития ИФПИ мог его достижения и недостатки сопоставлять с уровнем мировой и отечественной науки, не преувеличивая результаты работы ИФПИ, но и не преуменьшая их.

В книге представлены научные ресурсы Московского гуманитарного университета, которые определили и направленность его научной работы, и характер ее организации. Особенно важно, что ИФПИ продолжил линию Научно-исследовательского центра ВКШ, а в научном плане опирался на гуманистическую концепцию молодежи И. М. Ильинского. В. А. Луков в ряде своих статей показал суть этой концепции и ее роль в подготовке законопроекта «Об общих началах государственной молодежной политики в СССР» (1987-1991 гг.) (Луков В. А., 2006). Она определила судьбу НИЦ и заложила основы научной школы молодежных исследований МосГУ (Ковалева, Луков, Перинская, 2016; Ковалева и др., 2018).

На фоне выдвижения НИЦ в первый ряд исследовательских сообществ по молодежной проблематике в книге откровенно показаны проблемы и трудности первого этапа научно-исследовательской работы в изменившихся общественных условиях. ИФПИ (первоначально ИГИ - Институт гуманитарных исследований) как новая структура вузовской науки становилась постепенно и не без трудностей, но исходная организационная идея И. М. Ильнского оказалась наиболее продуктивной.

Автор подробно характеризует первые научные проекты ИФПИ, и в их числе такие, как Международная научная конференция «Высшее образование для XXI века», мониторинг «Российский вуз глазами студентов», междисциплинарное исследование «Студент Московского гуманитарного университета», научный журнал МосГУ «Знание. Понимание. Умение», Русский интеллектуальный клуб, Бунинская премия.

В плане выдвижения новых концепций в сфере гуманитарного знания интерес привлекает информация о постоянном методологическом семинаре «Тезаурусный анализ мировой культуры». Во второй главе, посвященной новым идеям и научным проектам ИФПИ, тезаурусный подход как методологическое средство в гуманитаристике изложен особенно подробно.

Теория и методология тезаурусного подхода представлены в книге В. А. Лукова в развитии. Если первоначально они связывались с литературове- 
дением и были поддержаны филологами ИФПИ (Захаров, 2008; Гайдин, 2009; Захаров, Гайдин, 2009), то через некоторое время к ним обратились философы (Ламажаа, 2013а; Тищенко, 2011), социологи (Гневашева, 2010; Луков С., 2013), культурологи (Костина, 2017), представители других наук. Монографии В. А. и Вл. А. Луковых «Тезаурусы» и «Тезаурусы ІІ» определили основные стороны тезаурусного подхода, повлияли на тематику проектов ИФПИ (Луков В., Луков Вл., 2008, 2013).

В аспекте тезаурусного подхода по-новому предстала дилемма «воспитание - понимание» (Луков, 2017), новые черты приобрело рассмотрение архаизации в переходном обществе (Ламажаa, 2013b), гуманитарной экспертизы (Юдин, Луков, 2006). Сформировалась оригинальная теория персональных моделей автора художественного произведения (Луков Вл., 2006). Нововведением в культурологии надо признать трактовки Н. В.Захаровым и Б. Н. Гайдиным шекспиросферы и марлосферы, как в целом применение ими вслед за Вл. А. Луковым сферного подхода к культурным константам (Луков Вл. А., 2014; Гайдин, 2014; Макаров, Захаров, Гайдин, 2016; Шекспиросфера ... , 2016; Захаров, 2018ab). Эти применения тезаурусного подхода подробно представлены в книге В. А. Лукова.

Особое внимание автор уделил возможностям концептуализации молодежи в формах теории. В том же году он выдвинул тезаурусную концепцию молодежи как основу своей докторской диссертации по социологии культуры (Луков, 2019b).

Перспективы ИФПИ автором обобщены в следующем виде: «Очевидно, что в новых поисках сохранен путь на развитие междисциплинарности и даже трансдисциплинарности, что сложные по составу и плохо формализуемые по наличию компонентов, а также многообразные последствиям проблемы (“кентавр-проблемы” в терминологии Ж. Т. Тощенко) привлекают особое внимание в ИФПИ. В ключе тезаурусного подхода, выражающего субъектную организацию знания, многие из обозначенных выше направлений могут получить более предметное выражение в той части, которая кажется внутренне противоречивой и не поддающейся логическому обоснованию. Развитие теории и методологии тезаурусного подхода важно не только потому, что его признание в научном сообществе относится к годам работы ИФПИ и с его именем связано, но этот подход проясняет некоторые стороны социального конструирования реальности, иначе или излишне абстрактные, или сведенные до ограниченных во времени и пространстве фактов.

Также из научного наследия ИФПИ в новых программах проявят себя уже не раз упоминавшиеся архаизация в регионах России, шекспиросфера, идея Русского мира, социокультурная субъектность, биосоциология молоде- 
жи, гуманитарная экспертиза и другие идеи, появившиеся или обретшие оригинальную форму в институте, но появится и новое качество исследований в быстро меняющемся российском обществе, которые позволят его лучше понять и более совершенно его развивать» (Луков, 2019а: 520).

В книге этот перечень убедительно показан как основа развития ИФПИ в прошлом, настоящем и будущем. Подтверждением этому служит огромная библиография работ института и его сотрудников: представлено 4500 книг, статей, сборников, номеров научных журналов, созданных в ИФПИ. Такая наиболее полная библиография дает картину ежедневного творчества коллектива, где видные деятели российской науки вместе с молодыми учеными закладывают новое здание гуманитарного знания, соответствующего ритмам XXI столетия.

\section{СПИСОК ЛИТЕРАТУРЫ}

Гайдин, Б. Н. (2009) Вечные образы в системе констант культуры // Знание. Понимание. Умение. № 2. С. 224-230.

Гайдин, Б. Н. (2014) Шекспиросфера в современном кино: постановка проблемы [Электронный ресурс] // Информационный гуманитарный портал «Знание. Понимание. Умение». № 4 (июль - август). URL: http://www.zpujournal.ru/e-zpu/2014/4/Gaydin_Shakespearean-Sphere-Cinema/ [архивировано в WaybackMachine] (дата обращения: 28.09.2019).

Гневашева, В. А. (2010) Социальные и культурные ценностные ориентации российской молодежи. М. : Изд-во Моск. гуманит. ун-та. 304 с.

Захаров, Н. В. (2008) Шекспиризм русской классической литературы: тезаурусный анализ. М. : Изд-во Моск. гуманит. ун-та. 320 с.

Захаров, Н. В. (2018а) Виртуальная шекспиросфера и портретные изображения Шекспира // Вестник Международной академии наук (Русская секция). № 1. С. 122-126.

Захаров, Н. В. (2018b) К. Марло и развлекательно-познавательная туриндустрия [Электронный ресурс] // Горизонты гуманитарного знания. № 6. C. 3-19. URL: http://journals.mosgu.ru/ggz/article/view/893 (дата обращения: 28.09.2019). DOI: $10.17805 / g g z .2018 .6 .1$

Захаров, Н. В., Гайдин, Б. Н. (2009) Шекспировская индустрия // Знание. Понимание. Умение. № 4. С. 246-250.

Ковалева, А. И. и др. (2018) Социология молодежи: научная школа Московского гуманитарного университета : в 2 ч. / А. И. Ковалева, В. А. Луков, В. А. Гневашева, С. В. Луков. М. : Изд-во Моск. гуманит. ун-та. Ч. 2. $508 \mathrm{c}$. 
Ковалева, А. И., Луков, В. А., Перинская, Н. А. (2016) Социология молодежи: научная школа Московского гуманитарного университета : в 2 ч. М. : Изд-во Моск. гуманит. ун-та. Ч. 1. 442 с.

Костина, А. В. (2017) Концепция тезауруса как методология современного научного знания о культуре // Тезаурусы и тезаурусная сфера: II Академические чтения памяти Владимира Андреевича Лукова, 29 марта 2017 г. : сб. науч. трудов. М. : Изд-во Моск. гуманит. ун-та. 256 с. С. 105-115.

Ламажаа, Ч. К. (2013а) Тувиноведение: новые горизонты. М. : Кн. дом «Либроком». $184 \mathrm{c.}$

Ламажаа, Ч. К. (2013b) Архаизация общества. Тувинский феномен. М. : Кн. дом «Либроком». 272 с.

Луков, В. А. (2006) Ильинский: гуманистическая концепция молодежи // Знание. Понимание. Умение. № 2. С. 48-59.

Луков, В. А. (2017) Проблемы понимания и воспитания // Знание. Понимание. Умение. № 3. С. 31-47. DOI: 10.17805/zpu.2017.3.3

Луков, В. А. (2019а) ИФПИ: люди, идеи, проекты, публикации: История, современное состояние, перспективы Института фундаментальных и прикладных исследований, его центров и отделов. Публикации ИФПИ и его сотрудников в 2004-2018 годах. М. : Изд-во Моск. гуманит. ун-та. 524 с.

Луков, В. А. (2019b) Социокультурные основания субъектности российской молодежи (тезаурусная концепция молодежи) : автореф. дис. ... д-ра социол. наук. М. 42 с.

Луков, В. А., Луков Вл. А. (2008) Тезаурусы: субъектная организация гуманитарного знания : науч. монография. М. : Изд-во Нац. ин-та бизнеса. $784 \mathrm{c}$.

Луков, В. А., Луков Вл. А. (2013) Тезаурусы ІІ: тезаурусный подход к пониманию человека и его мира : науч. монография. М. : Изд-во Национального института бизнеса. $640 \mathrm{c}$.

Луков, Вл. А. (2006) Теория персональных моделей в истории литературы : науч. монография. М. : Изд-во Моск. гуманит. ун-та. 103 с.

Луков, С. В. (2013) Диалог организационных культур в современной России: тезаурусный подход // Тезаурусный анализ мировой культуры : сб. науч. трудов. Вып. 25 / под общ. ред. Вл. А. Лукова. М. : Изд-во Моск. гуманит. ун-та. 160 с. С. 123-131.

Макаров, В. С., Захаров, Н. В., Гайдин, Б. Н. (2016) Шекспиросфера в год четырехсотлетия бессмертия поэта // Знание. Понимание. Умение. № 4. C. 275-302. DOI: 10.17805/zpu.2016.4.24

Тищенко, П. Д. (2011) Знание, понимание, умение в герменевтической структуре научного текста // Знание. Понимание. Умение. № 1. С. 58-67. 
Шекспиросфера: виртуальные миры Шекспира и его современников (2016) : коллективная монография / гл. ред. И. И. Лисович ; ред.: В. С. Макаров, Б. Н. Гайдин. М. : Изд-во Моск. гуманит. ун-та. 480 с.

Юдин, Б. Г., Луков, В. А. (2006) Гуманитарная экспертиза: к обоснованию исследовательского проекта. М. : Изд-во Моск. гуманит. ун-та. 38 с.

Дата поступления: 30.09.2019 г.

\section{REFERENCES}

Gaydin, B. N. (2009) Vechnye obrazy v sisteme konstant kul'tury [Eternal images in the system of constants of culture]. Znanie. Ponimanie. Umenie, no. 2, pp. 224-230. (In Russ.).

Gaydin, B. N. (2014) Shekspirosfera v sovremennom kino: postanovka problemy [The Shakespearean sphere in contemporary cinema: The problem definition]. Informatsionnyi gumanitarnyi portal "Znanie. Ponimanie. Umenie”, no. 4 (July — August). [online] Available at: http://zpu-journal.ru/e-zpu/2014/4/Gaydin _Shakespearean-Sphere-Cinema/ [archived in WaybackMachine] (accessed 28.09. 2019). (In Russ.).

Gnevasheva, V. A. (2010) Sotsial'nye i kul'turnye tsennostnye orientatsii rossiiskoi molodezhi [Social and cultural value orientations of the Russian youth]. Moscow : Moscow University for the Humanities Publ. 304 p. (In Russ.).

Zakharov, N. V. (2008) Shekspirizm russkoi klassicheskoi literatury: tezaurusnyi analiz [Shakespearianism of Russian classical literature: The thesaurus analysis]. Moscow : Moscow University for the Humanities Publ. 320 p. (In Russ.).

Zakharov, N. V. (2018a) Virtual'naia shekspirosfera i portretnye izobrazheniia Shekspira [The virtual Shakespearean sphere and portraits of Shakespeare]. Vestnik Mezhdunarodnoi akademii nauk (Russkaia sektsiia), no. 1, pp. 122-126. (In Russ.).

Zakharov, N. V. (2018b) K. Marlo i razvlekatel'no-poznavatel'naia turindustriia [C. Marlowe and edutainment tourist industry]. Gorizonty gumanitarnogo znaniia, no. 6, pp. 3-19. [online] Available at: http://journals.mosgu.ru/ggz/article/ view/893 (accessed 28.09.2019). (In Russ.). DOI: 10.17805/ggz.2018.6.1

Zakharov, N. V. and Gaydin, B. N. (2009) Shekspirovskaia industriia [Shakespeare industry]. Znanie. Ponimanie. Umenie, no. 4, pp. 246-250. (In Russ.).

Kovaleva, A. I. et al. (2018) Sotsiologiia molodezhi: nauchnaia shkola Moskovskogo gumanitarnogo universiteta [Sociology of the youth: The school of thought at Moscow University for the Humanities] : in 2 pts. / A. I. Kovaleva, 
V. A. Lukov, V. A. Gnevasheva and S. V. Lukov. Moscow : Moscow University for the Humanities Publ. Pt. 2. 508 p. (In Russ.).

Kovaleva, A. I., Lukov, V. A. and Perinskaia, N. A. (2016) Sotsiologiia molodezhi: nauchnaia shkola Moskovskogo gumanitarnogo universiteta [Sociology of the youth: The school of thought at Moscow University for the Humanities] : in 2 pts. Moscow : Moscow University for the Humanities Publ. Pt. 1. 442 p. (In Russ.).

Kostina, A. V. (2017) Kontseptsiia tezaurusa kak metodologiia sovremennogo nauchnogo znaniia o kul'ture [Conception of thesaurus as a methodology of contemporary academic knowledge on culture]. In: Tezaurusy i tezaurusnaia sfera [Thesauri and thesaurus sphere]: The 2nd Academic Readings in the memory of Vladimir Andreevich Lukov, March 29, 2017 : A collection of articles. Moscow : Moscow University for the Humanities Publ. 256 p. Pp. 105-115. (In Russ.).

Lamazhaa, Ch. K. (2013a) Tuvinovedenie: novye gorizonty [Tuvan studies: The new horizons]. Moscow : Librokom Publ. House. 184 p. (In Russ.).

Lamazhaa, Ch. K. (2013b) Arkhaizatsiia obshchestva. Tuvinskii fenomen [Archaization of society. The Tuvan phenomenon]. Moscow : Librokom Publ. House. 272 p. (In Russ.).

Lukov, V. A. (2006) Ilinskiy: gumanisticheskaia kontseptsiia molodezhi [Ilinskiy: A humanist concept of youth]. Znanie. Ponimanie. Umenie, no. 2, pp. 48-59. (In Russ.).

Lukov, V. A. (2017) Problemy ponimaniia i vospitaniia [Problems of understanding and personality development]. Znanie. Ponimanie. Umenie, no. 3, pp. 3147. (In Russ.). DOI: 10.17805/zpu.2017.3.3

Lukov, V. A. (2019a) IFPI: liudi, idei, proekty, publikatsii: Istoriia, sovremennoe sostoianie, perspektivy Instituta fundamental'nykh i prikladnykh issledovanii, ego tsentrov $i$ otdelov. Publikatsii IFPI i ego sotrudnikov v 2004-2018 godakh [IFAS: People, ideas, projects, publications: History, current state, prospects of the Institute of Fundamental and Applied Studies, its centers and departments. Publications of the IFAS and its employees in 2004-2018]. Moscow : Moscow University for the Humanities Publ. 524 p. (In Russ.).

Lukov, V. A. (2019b) Sotsiokul'turnye osnovaniia sub"ektnosti rossiiskoi molodezhi (tezaurusnaia kontseptsiia molodezhi) [Sociocultural foundations of the Russian youth's subjectivity (Thesaurus conception of the youth)] : Abstract of the diss. ... Doctor of Sociology. Moscow. 42 p. (In Russ.).

Lukov, V. A. and Lukov, Vl. A. (2008) Tezaurusy: Sub"ektnaia organizatsiia gumanitarnogo znaniia [Thesauri: The subjective organization of humanities knowledge]. Moscow : The National Institute of Business Publ. 784 p. (In Russ.). 
Lukov, V. A. and Lukov, Vl. A. (2013) Tezaurusy II: Tezaurusnyi podkhod $k$ ponimaniiu cheloveka i ego mira [Thesauri II: The thesaurus approach to the conceptualization of the person and his/her world]. Moscow : The National Institute of Business Publ. 640 p. (In Russ.).

Lukov, Vl. A. (2006) Teoriia personal'nykh modelei v istorii literatury [The theory of personal models in literary history]. Moscow : Moscow University for the Humanities Publ. 103 p. (In Russ.).

Lukov, S. V. (2013) Dialog organizatsionnykh kul'tur v sovremennoi Rossii: tezaurusnyi podkhod [Dialogue of organizational cultures in contemporary Russia: Thesaurus approach]. In: Tezaurusnyi analiz mirovoi kul'tury Thesaurus analysis of world culture] : A collection of research articles. Issue 25 / ed. by Vl. A. Lukov. Moscow : Moscow University for the Humanities Publ. 160 p. P. 123-131. (In Russ.).

Makarov, V. S., Zakharov, N. V. and Gaydin, B. N. (2016) Shekspirosfera v god chetyrekhsotletiia bessmertiia poeta [The Shakespearean sphere in the year of the 400th anniversary of poet's immortality]. Znanie. Ponimanie. Umenie, no. 4, pp. 275-302. (In Russ.). DOI: 10.17805/zpu.2016.4.24

Tishchenko, P. D. (2011) Znanie, ponimanie, umenie v germenevticheskoi strukture nauchnogo teksta [Knowledge, understanding and skill in hermeneutic structure of scientific text]. Znanie. Ponimanie. Umenie, no. 1, pp. 58-67. (In Russ.).

Shekspirosfera: virtual'nye miry Shekspira i ego sovremennikov [The Shakespearean sphere: Virtual worlds of Shakespeare and his contemporaries] (2016) : A multi-authored monograph / ed. by I. I. Lisovich, V. S. Makarov and B. N. Gaydin. Moscow : Moscow University for the Humanities Publ. 480 p. (In Russ.).

Yudin, B. G. and Lukov, V. A. (2006) Gumanitarnaia ekspertiza: K obosnovaniiu issledovatel'skogo proekta [Expert evaluation in the humanities: Substantiation of the research project]. Moscow : Moscow University for the Humanities Publ. 38 p. (In Russ.).

Submission date: 30.09.2019.

Лихачев Михаил Васильевич - кандидат социологических наук, независимый исследователь (г. Рязань). Эл. адрес: m.v.lihachev@mail.ru

Likhachev Mikhail Vasilievich, Candidate of Sociology, independent researcher (Ryazan City).E-mail: m.v.lihachev@mail.ru 
Для циитирования:

Лихачев М. В. ИФПИ как источник новых концепций в сфере гуманитарного знания [Электронный ресурс] // Горизонты гуманитарного знания. 2019. № 5. С. 128-136. URL: http://journals.mosgu.ru/ggz/article/view/1111 (дата обращения: дд.мм.гггг). DOI: 10.17805/ggz.2019.5.8 